the $\beta$. They state however that it is impossible to convert one directly into the other. A much more plausible explanation is that the $\alpha$ being prepared from cis indigo directly is optically inactive diacetyl indigo white (by internal compensation-similar to mesotartaric acid), whereas the $\beta$ is prepared from trans diacetyl indigo and is therefore a racemic mixture capable of being resolved into its optically active constituents.

The work on indigo is being continued.

I. AHORATORY OF ORGAXIC CHEMISTIR:

September, Igo7.

[CONTRIBUTION FROM THE HAVEMEYER LABORATORIES OF COLUMBIA UNIVERSITY, No. I48.]

\title{
EXPERIMENTS UPON BARFOED'S ACID CUPRIC ACETATE SOLU- TION AS A MEANS OF DISTINGUISHING GLUCOSE FROM MALTOSE, LACTOSE AND SUCROSE.
}

BY F. C. HINKEL AND H. C. SHERMAN.

Received October 3, 1907.

In some preliminary work upon the Barfoed test carried out in this laboratory by $\mathrm{L}$. J. Cohen in $1905^{1}$, it appeared to be practicable to distinguish between glucose and maltose in solutions containing less than 0.02 per cent. of the former and at least as much as 0.2 per cent. of the latter, provided the tests are controlled by check experiments with knowu solutions of the sugars. These results seemed sufficiently favorable to warrant further experiment. The details of the test as used both in Cohen's experiments and in those described below are as follows :

Reagent: Dissolve $45 \mathrm{~g}$. of neutral crystallized cupric acetate in 900 cc. of water, filter if necessary; add I. 2 cc. of 50 per cent. acetic acid and dilute to a liter. A portion of this reagent must show no change when heated in a boiling water-bath for Io minutes, and on long. er heating only a turbidity due to volatilization of acetic acid and formation of basic salt.

Test: To $5 \mathrm{cc}$. of the reagent in a test tube add the solution to be tested and stand the tube in a water-bath of such depth that the tube is surrounded by boiling water to at least the level of the liquid within. After $3 \frac{1}{2}$ minutes remove the tube from the water-bath and examine for cuprous oxide, viewing the tube against a black background in a good light. If no evidence of reduction is found, allow the tube to stand at room temperature for 5 or 10 minutes and examine again. For uniform results the different tubes used in making the tests should be of nearly the same diameter and thickness of wall. It is sometimes advantageous to pour out the liquid at the end of the test, leaving any cuprous oxide as far as possible adhering to the bottom of the test tube and examine again.

${ }^{1}$ Sherman's Methods of Organic Analysis, pp. 75-76. 


\section{Experiments with Known Solutions.}

The tests described below were made in order to ascertain the delicacy and reliability of this method for distinguishing glucose from maltose, lactose and sucrose, both in pure solutions and in mixtures.

\begin{tabular}{|c|c|c|c|c|c|c|}
\hline \multirow{3}{*}{$\begin{array}{c}\text { Sugar } \\
\text { tested } \\
\text { Glucose }\end{array}$} & \multicolumn{3}{|c|}{ EXPERIMENTS WIT } & \multicolumn{3}{|c|}{ KNOWN SOLUTIONS. } \\
\hline & \multicolumn{2}{|c|}{$\begin{array}{l}\text { Volume of } \\
\text { reagent }\end{array}$} & \multirow{3}{*}{$\begin{array}{l}\text { Volume of } \\
\text { sugar solution } \\
\text { I. cc. } \\
0.5 \text { " }\end{array}$} & \multicolumn{2}{|c|}{$\begin{array}{l}\text { Weight of } \\
\text { sugar present }\end{array}$} & \multirow{2}{*}{$\begin{array}{c}\text { Result of } 31 / 2 \\
\text { minutes heating } \\
\text { Distinct reduction }\end{array}$} \\
\hline & & cc. & & $0.00 \mathrm{I}$ & gram. & \\
\hline \multirow{9}{*}{ Maitose } & 5 & $"$ & & 0.0005 & " & Slight \\
\hline & 5 & “ & 5. " " & 0.0002 & " & Very slight “" \\
\hline & 5 & " & I0. " " & 0.0001 & " & Doubtful \\
\hline & 5 & ، & I. " " & 0.0002 & “ & Slight reduction \\
\hline & 5 & $\mathrm{cc}$. & 4. cc. & 0.04 & gram. & Slight reduction \\
\hline & 5 & $"$ " & 3. " " & 0.03 & ، & " $"$ " \\
\hline & 5 & “ & $2.5 " 1$ & 0.025 & " & Very slight " \\
\hline & 5 & “ & 2. ، & 0.02 & “" & No reduction ${ }^{2}$ \\
\hline & 5 & “ & I. " & 0.025 & “ & Very slight reduction \\
\hline \multirow{5}{*}{ Lactose } & 5 & “ & 5. “ & 0.025 & “ & $\because$ \\
\hline & 5 & $" 1$ & Io. " & 0.025 & .1 & $" ،$ \\
\hline & 5 & cc. & 3. cc. & 0.03 & gram. & \multirow{2}{*}{$\begin{array}{l}\text { Slight reduction } \\
\text { Very slight reduction }\end{array}$} \\
\hline & 5 & $"$ & $2.5^{\prime \prime}$ & 0.025 & “ & \\
\hline & 5 & $"$ & 2. " " & 0.02 & “ & No reduction ${ }^{2}$ \\
\hline \multirow{7}{*}{ Sucrose } & 5 & " & I. " & 0.025 & “ & Slight "، \\
\hline & 5 & " & 5. ، & 0.025 & " & Very slight reduction \\
\hline & 5 & “" & 10. " " & 0.025 & “ & " \\
\hline & & cc. & 3. $\mathrm{cc}$. & 0.03 & gram. & No reduction ${ }^{3}$ \\
\hline & 5 & " & I. " " & 0.025 & “ & $"$ \\
\hline & 5 & ، & 5. " & 0.025 & . & $" ،$ \\
\hline & 5 & “ & 10. " " & 0.025 & “ & " \\
\hline
\end{tabular}

The figures given in the table indicate that when the test is carried out as described, the results depend more largely upon the actual amount of sugar present than upon the volume of water in which the sugar is dissolved.

In this series of tests 0.0002 to $0.0005 \mathrm{~g}$. glucose gave a slight but perceptible reduction under the conditions adopted. Under the same conditions no reductions were observed with $0.02 \mathrm{~g}$. maltose or lactose or with $0.03 \mathrm{~g}$. sucrose. The addition of these amounts of disaccharides to solutions containing known amounts of glucose did not appear to have any marked effect.

\section{Experiments With Unknown Solutions.}

As a further test of the method, solutions were prepared by one of us and given to the other for test.

In each case the experimenter was told that the solution submitted contained I per cent. of total sugar which might be either a single disac-

${ }^{2}$ Very slight reduction on heating for 6 minutes.

'Slight reduction on heating for 6 minutes.

${ }^{3}$ Slight reduction on beating for 6 minutes.

+ Slight reduction on heating for 8 minutes. 
charide or a mixture of disaccharide and glucose, and was requested to de. cide (by means of the test above) which of the samples contained glucose and to arrange them in order of the amount present. These experiments upon unknown solutions, mostly mixtures, gave the following results :

Solutions Containing Sucrose. Five solutions were prepared containing respectively (I) Sucrose 0.96 per ceut.; glucose 0.04 per cent. (2) Sucrose 0.97 per cent.; glucose 0.03 per cent. (3) Sucrose 0.98 per cent.; glucose 0.02 per cent. (4) Sucrose 0.99 per cent.; glucose 0.01 per cent. (5) Sucrose 1.0 per cent.; glucose, none.

The experimenter, knowing only that the total sugar was in each case I per cent. of the solution, used only $2 \mathrm{cc}$. (containing $0.02 \mathrm{~g}$. total sugar) for each test, so as to avoid appreciable reduction due to disaccharide alone. The first three solutions were found to contain glucose and were arranged correctly with reference to the amounts present.

Solutions Containing Lactose. Five samples parallel with those just described, but containing lactose instead of sucrose were prepared and tested in the same manner and with the same results.

Solutions Containing Maltose. These were also prepared and tested in the same way as the solutions containing sucrose and again no glucose was found when only $0.0002 \mathrm{~g}$. was present but the other tubes all showed reduction and were correctly arranged in order of glucose content.

With known solutions containing glucose only, it seemed possible to note an effect upon the reagent when only $0.0002 \mathrm{~g}$. glucose was present, whereas in each of the three sets of unknown solutions containing disaccharides the limit of delicacy of the test seemed to be reached at about $0.0004 \mathrm{~g}$. It is not believed that this apparent discrepancy indicates an interference due to the disaccharide, ${ }^{2}$ but rather that a very minute reduction which was accepted as a positive test in known glucose solutions where other sugars were absent, did not appear sufficiently convincing in unknown solutions where relatively large amounts of a disaccharide were presumably present.

Thus in unknown solutions containing approximately I per cent. $(0.02$ gram.) of either sucrose, lactose or maltose, the test sufficed to distinguish the presence of 0.02 per cent. ( 0.0004 gram.) of glucose and to show differences of 0.0 r per cent. The test has also been found useful in the detection of glucose in the presence of nine times its weight of a mixture containing the three disaccharides mentioned.

\section{Experiments Upon Complete Destruction of Glucose.}

Since it has been proposed to detect glucose in sugar mixtures by means of Barfoed solution and than use the filtrate for the detection of maltose or lactose ${ }^{2}$, it becomes important to know, not only the mininum amount

'Such as the interference of maltose and lactose with the osazone test for glucose, this Journal, 28, 629 .

'Bartley and Mayer, Merck's Report, 12, 100 (1903). 
of glucose which can be detected, but also the maximum amount which will be completely destroyed, since presence of undestroyed glucose would obviously render useless any reduction tests for maltose or lactose in the filtrate.

In the experiments upon this point, known amounts of glucose each contained in $5 \mathrm{cc}$. of water, were treated with $5 \mathrm{cc}$. of the reagent as above described and after $31 / 2$ minutes heating were filtered, the filtration repeated if necessary, until a clear filtrate was obtained and this was then boiled gently for 2 minutes over a free flame. This was repeated with diminishing amounts of glucose until the two minutes boiling of the acid filtrate showed no further reduction, but when such a filtrate was mixed with Fehling's alkaline tartrate solution before boiling a reduction occured indicating incomplete destruction of the glucose by the Barfoed solution. The tests were continued to find how much glucose would be so completely destroyed by the Barfoed solution as here used, that the filtrate would give no evidence of reducirg sugar on mixing with alkaline tartrate and boiling for 2 minutes. This amount of glucose was found to be 0.0025 to 0.003 gram. Hence it appears that if the Barfoed test be used as part of a general scheme for sugar mixtures in the manner proposed by Bartley and Mayer, the amount of glucose (or of total monosaccharide calculated as glucose) present in the portion of solutiont ested, should not exceed 2 milligrams for $5 \mathrm{cc}$. of the acid cupric acetate reagent.

\section{Conclusions.}

On account of the difficulty of securing an exact degree of acidity in the cupric acetate solution, each chemist should demonstrate the efficiency of his reagent, as well as verify his manipulation, by check experiments upon known sugar solutions covering the probable range of composition of the unknown solutions to be tested.

As here described the test was efficient for the detection of 0.0004 gram. of glucose, either alone or in the presence of maltose, lactose or sucrose up to 0.02 gram.

Reduction due to disaccharide occurs if too much either of sugar or of acid be present, or if the heating be too prolonged.

In order to effect complete destruction of the glucose, so that the filtrate might be utilized in testing for maltose or lactose, it was necessary to limit the amount to about 0.002 gram of glucose to $5 \mathrm{cc}$. of the reagent.

It appears that the test requires very careful regulation as to details of manipulation and amount of sugar tested, but under such restrictions is capable of greater usefulness than has generally been appreciated.

\section{A TRIAL OF THE POLARISCOPIC METHOD FOR THE DETERMIN- ATION OF GLIADIN.

In Vol. XXVI, No. 3, of this Journal, Professor Harry Snyder sug- 